\title{
Association Between Sleep Quality and Physical Activity in Saudi Arabian University Students
}

This article was published in the following Dove Press journal:

Nature and Science of Sleep

\author{
Mohamed Salih Mahfouz (D' \\ Suhaila Abdalkarim Ali (D) \\ Alanoud Yahya Bahari ${ }^{2, *}$ \\ Reham Eissa Ajeebi ${ }^{2, *}$ \\ Hadeel Jaber Sabei ${ }^{2, *}$ \\ Sara Yahya Somaily ${ }^{2, *}$ \\ Yusra Ahmed Madkhali ${ }^{2, *}$ \\ Reem Hady Hrooby ${ }^{2, *}$ \\ Roa'a Nasser Shook ${ }^{2, *}$ \\ 'Department of Family and Community \\ Medicine, Faculty of Medicine, Jazan \\ University, Jazan, Kingdom of Saudi \\ Arabia; ${ }^{2}$ Faculty of Medicine, Jazan \\ University, Jazan, Kingdom of Saudi \\ Arabia
}

*These authors contributed equally to this work
Background: Many studies have documented a strong association between poor sleep quality and physical inactivity. This study evaluates the association between poor sleep quality and physical inactivity among Jazan University students in Saudi Arabia.

Methods: An observational cross-sectional study was conducted among undergraduate students at Jazan University. Cluster random sampling was used to select 440 students. The Pittsburgh Sleep Quality Index (PSQI), International Physical Activity Questionnaire (IPAQ), and Depression Anxiety Stress Scales (DASS) were utilized for data collection.

Results: According to the PSQI results, the majority of respondents $(63.9 \% ; n=281)$ reported having poor sleep quality. The majority of students $(62.7 \% ; n=276)$ were also physically inactive. Based on DASS-21 criteria, the majority of students (53.4\%) were stressed. Sleep quality differed significantly according to participants' physical activity status $(p=0.0090)$. Among physically active participants, $43.9 \%$ reported having good sleep quality. Sleep duration, daytime dysfunctions, and global PSQI differed significantly according to levels of physical activity ( $p<0.05$ for all). Univariate analysis revealed that being physically active was significantly associated with good sleep quality $(\mathrm{OR}=1.70,95 \%$ CI $1.14-2.54, p<0.001)$. Multivariate logistic regression models also demonstrated a significant association between physical activity and good sleep quality (OR $=1.72,95 \%$ CI $1.15-2.56, p=0.008)$.

Conclusion: The majority of Jazan University students had poor sleep quality and were physically inactive. Evidence-based prevention and therapeutic strategies are needed to promote physical activity among university students.

Keywords: sleep quality, PSQI, physical inactivity, Jazan

\section{Introduction}

Sleep is a vital physiological process that plays an important role in human bodily functions. ${ }^{1}$ Sleep disorders are common and affect sleep quality and quantity, leading to increased morbidity. Patients with sleep disorders can be categorized as those who cannot sleep, those who will not sleep, those with excessive daytime sleepiness, and those with increased movement during sleep. ${ }^{2,3}$ Sleep disorders are associated with several morbidities, mainly psychiatric disorders such as stress, depression, addictions, and dementia, and may lead to deaths due to suicide, as well as gastrointestinal diseases such as GERD, dyspepsia, and IBS and circulatory diseases including coronary heart disease, heart failure, and stroke/transient ischemic attack. ${ }^{4}$ Sleep has a crucial impact on cognitive functioning, productivity, and academic performance. 5,6

University study is associated with a radical change in life patterns for undergraduate students. They are faced with increased independence, changes in peer
Correspondence: Mohamed Salih Mahfouz

Email mm.mahfouz@gmail.com 
groups, a new social life, and increased academic responsibilities. These challenges are normally associated with an unhealthy lifestyle, sleep disorder, and in some cases, substance abuse. ${ }^{7-10}$

Most research conducted in the Kingdom of Saudi Arabia (KSA) during the past 20 years to measure sleep quality among university students has limited its focus to medical students. These studies have shown a very high prevalence of poor sleep quality, daytime sleepiness, and insomnia. ${ }^{11-15}$ A study conducted among 2,095 adults in Riyadh showed that one in every three Saudi adults is suffering from short sleep duration of less than 7 hours per night. ${ }^{16}$ Another study strongly related short sleep duration among Saudi adolescents to an increased risk of overweight and obesity. ${ }^{17}$

Physical activity is defined as "any body movement produced by skeletal muscles that results in energy expenditure". ${ }^{18}$ A lack of physical activity is a major risk factor for non-communicable disease (NCDs), and studies show that people who exercise regularly have a lower risk of developing coronary artery disease, diabetes mellitus, obesity, hypertension and joint diseases than people who do not. ${ }^{19}$

Many observational studies conducted in Saudi Arabia show a high prevalence of physical inactivity, ranging from $43 \%$ to $80 \%$ of the population. This is especially common among females, regardless of regional variation. Most Saudi adults are not active enough to meet the minimal weekly requirements of moderate to vigorous physical activity that are recommended by international guidelines. ${ }^{20,21}$

University students in Saudi Arabia are also facing the risks that result from physical inactivity. ${ }^{22}$ Many studies have been done at universities in the KSA to show just how insufficient students' physical activity is. Students reported the following barriers that discouraged them from engaging in physical activity: a lack of time, a lack of suitable places to exercise, and a lack of support from family and friends. ${ }^{23,24}$ Many studies have documented the strong association between poor sleep quality and physical inactivity. ${ }^{25-31}$ Hence, this study aims to evaluate the association between poor sleep quality and physical inactivity among Jazan University students, since numerous studies reveal that students suffer from poor sleep quality ${ }^{32}$ and have low rates of participation in physical activity. ${ }^{20,21}$

\section{Materials and Methods}

\section{Ethical Considerations}

The study was conducted following the Ethical Standard of Saudi Arabia and complied with the Declaration of
Helsinki. Ethical clearance was obtained from the Jazan University Ethical Committee (REC 40/3-083). All study participants read, understood, and signed the written consent. The researchers respected both the privacy and the confidentiality of study participants. The data were kept and only used for scientific purposes. The participants were told that they had the right to withdraw at any time.

\section{Study Setting, Design, and Population}

The research was conducted at Jazan University, which is located in the city of Jazan. Jazan lies in the southwestern corner of Saudi Arabia and has a population of 1,567,547 as of the 2017 census. Jazan University is a leading educational institution in the region. It was established in 2006 and has more than 50,000 students. The university includes 18 colleges and four research centres. The study targeted university students aged 19-27 years. Cases were drawn from all students at Jazan University who were registered for the 2018/2019 academic year.

\section{Sampling Procedures}

The sample size for this study was calculated as 450 students using the sample size formula for studies organized according to a cross-sectional study design. The study uses the parameters of $p=50 \%$ to provide the maximum sample size, $95 \%$ confidence interval, and error not more than 5\%. Also, the study assumed a non-response rate of $25 \%$. The sampling design used was cluster random sampling. The study divides the university faculties into three groups: medical, scientific, and arts colleges. Two faculties were randomly selected from each stratum. The selected colleges included the faculty of the Medicine and Applied Medical College, which represented the clinical sciences; the Scientific and Computing and Information Technology colleges, which represented the scientific sector; finally, the art and humanities group was represented by the Colleges of Arts and Business Administration.

\section{Data Collection}

The study questionnaire was distributed to the participants by the study team. We visited the students at their colleges and asked them to complete the self-administered questionnaire. Three structured and validated international questionnaires were used to collect the information from the study participants: IPAQ,${ }^{33}$ PSQI,${ }^{34}$ and DASS. ${ }^{35}$ The first part of the questionnaire collected information related to the participants' socio-demographic details, such as age, gender, college, GPA, marital status, residence, and income. 
The second part collected information about the physical activity using a short version of IPAQ. The third part was intended to assess sleep quality and factors affecting sleep quality using PSQI. The final part involved questions on depression, anxiety, and stress from DASS. Pre-testing of the questionnaire was conducted among the Faculty of Medicine students using 20 questionnaires. The main objective of the pre-testing was to determine the adequacy of the questionnaire and sample design, length of the interview and respondents' perception of the questionnaires' content and sequence of topics. The reliability of the three instruments was assessed during this stage using Cronbach's alpha and produced acceptable values greater than 0.70 .

\section{IPAQ, PSQI, and DASS}

The IPAQ short form was utilized for this study by asking about three specific types of activity, namely walking, moderate-intensity activities, and vigorous-intensity activities. The items were structured to provide separate scores on walking, moderate-intensity activity, and vigorousintensity activity. Computation of the total score for the short form requires the summation of the duration (in minutes) and frequency (days) of walking, moderateintensity activity, and vigorous-intensity activity. ${ }^{36}$ PSQI was used to measure the quality and patterns of sleep. Consisting of 19 items, it differentiates "poor" from "good" sleep by measuring seven domains: subjective sleep quality, sleep latency, sleep duration, habitual sleep efficiency, sleep disturbances, use of sleep medication, and daytime dysfunction over the last month. Scoring of the answers is based on a 0 to 3 scale, where 3 reflects the negative extreme on the Likert Scale. The global PSQI score is calculated by totalling the seven component scores, providing an overall score ranging from 0 to 21 , where lower scores denote healthier sleep quality. ${ }^{34}$ DASS is a set of three self-report scales designed to measure the negative emotional states of depression, anxiety, and stress. It is made up of seven self-report items, each reflecting a negative emotional symptom. Each of these is rated on a 4-point Likert scale of the frequency or severity of the participants' experiences over the last week to emphasize states over traits. ${ }^{37}$

\section{Statistical Analysis and Data Processing}

Frequency distributions were obtained, and descriptive statistics were calculated. First, numerical variables were tested for normality; an independent $t$-test and one-way ANOVA were used to compare groups. A Kruskal-Wallis Test was used for one variable that was not normally distributed. A chi-square test was used to determine the association between sleep quality and selected characteristics. Another level of analysis using multiple linear regression and logistic regression analyses were run with sleep quality as the outcome variable. In the regression models, we controlled for stress as the main confounder. Results are reported as odds ratios (OR) with 95\% confidence intervals. The data entry and analysis were performed using IBM Statistics SPSS version 20 (SPSS Inc, NY, USA) software. A $p$-value of less than 0.05 was used to indicate statistical significance.

\section{Results}

Four hundred forty students completed the questionnaires, giving a response rate of $97.8 \%$ (440 out of 450). Respondents' ages ranged from 19 to 27 years, with a mean, median, and mode of $22.38,22$, and 22 years, respectively $(\mathrm{SD}=1.6)$. Table 1 shows the sociodemographic distribution of the study population. Health-related colleges included those of medicine and applied medical sciences, which together constituted $33.6 \%$ of the respondent pool. Other science colleges included those of science and computer science, which together constituted 33.4\% of respondents. Humanities, including business administration and the faculty of education, accounted for $33 \%$ of respondents. About $48.9 \%$ of students were male, while $51.1 \%$ were female. The majority of students were single $(86.8 \%)$, and $11.1 \%$ of the respondents' fathers were

Table I Sociodemographic Characteristics of Study Population, 2019

\begin{tabular}{|l|l|l|l|l|l|}
\hline Characteristics & N & $\%$ & Characteristics & N & $\%$ \\
\hline Gender & 215 & 48.9 & Married & 58 & 13.2 \\
Male & 225 & 51.1 & Single & 382 & 81.8 \\
Female & \multicolumn{5}{|l|}{ Monthly Income (Saudi Riyals) } \\
\hline Age Groups & 56 & 12.7 & Less than 5,000 & 129 & 29.3 \\
\hline 19-20 Years & 177 & 40.2 & $5,000-9,999$ & 131 & 29.8 \\
21-22 Years & 173 & 39.3 & I0,000-14,999 & 79 & 18.0 \\
23-24 Years & 34 & 7.7 & $15,000+$ & 100 & 22.7 \\
25+ Years & 77 & 17.5 & Health & 148 & 33.6 \\
\hline GPA & 151 & 34.3 & Humanities & 145 & 33.0 \\
\hline $4.50-5.0$ & 140 & 31.8 & Scientific & 147 & 33.4 \\
$3.75-4.49$ & 56 & 12.7 & Total & 440 & 100.0 \\
$2.75-3.74$ & $2.0-2.74$ &
\end{tabular}


reported to be illiterate. Only $19.8 \%$ of mothers and $36.1 \%$ of fathers had university degrees or higher.

Table 2 presents the patterns of sleep quality, physical activity and stress levels according to the participants' gender. The table shows that according to PSQI, two-thirds of study participants $(63.9 \% ; n=281)$ were poor sleepers, compared with $36.1 \%(n=159)$ of the sample who reported having good sleep quality. No significant differences in sleep quality were reported according to gender $(p=0.795)$. The majority of students were physically inactive $(62.7 \% ; \mathrm{n}=276)$. We found that $30.5 \%(\mathrm{n}=134)$ of students were moderately physically active, while $6.8 \%(\mathrm{n}=30)$ were highly physically active. In relation to gender, we found that $72.4 \%$ of female students were physically inactive, compared with 52.6\% of males, which indicates a significant gender difference $(p<0.001)$. Based on DASS-21 criteria, a majority of students were stressed (53.4\%). No significant difference was observed between males' and females' stress levels $(p=0.217)$.

Factors associated with sleep quality among the study participants are shown in Table 3. Sleep quality differed significantly according to participants' physical activity status $(p=0.0090)$. Among the respondents, $43.9 \%(\mathrm{n}=72)$ of physically active participants reported having good sleep quality, while only $31.5 \%(\mathrm{n}=87)$ of physically inactive participants reported enjoying good sleep quality. A more detailed account of physical activity further supports this interpretation, since $56.7 \%(\mathrm{n}=17)$ of highly physically active students had good sleep quality, compared with $41.0 \%$ $(n=55)$ of moderately active students. No statistical difference in sleep quality was observed according to stress, stress level, caffeine intake, or tobacco use ( $p>0.05$ for all).

Sleep quality according to the different physical activity levels among the study participants is presented in Table 4. Sleep duration, daytime dysfunctions, and global PSQI differed significantly according to the level of physical activity ( $p<0.05$ for all). The mean PSQI score was higher for physically inactive students than for moderately or highly active students, with values of $7.1 \pm 2.8,6.4 \pm 2.9$, and $5.1 \pm 2.6$, respectively.

Table 5 shows the results of the logistic regression and multiple linear regression models for potential factors associated with good sleep quality. Univariate analysis revealed that being physically active was significantly associated with good sleep quality $(\mathrm{OR}=1.70,95 \%$ CI $1.14-2.54$, $p<0.001)$. The multivariate logistic regression models also indicated a significant association between physical activity and good sleep quality $(\mathrm{OR}=1.72, p=0.008)$. The multiple linear regression model further showed lower levels of PSQI to be significantly associated with increased days of physical activity $(\beta=-.167, p<001)$.

Table 2 Sleep Quality, Physical Activity, and Stress According to Gender Among Study Participants

\begin{tabular}{|c|c|c|c|c|}
\hline Characteristics & $\begin{array}{l}\text { Total } \\
\text { N\% }\end{array}$ & $\begin{array}{l}\text { Male } \\
\text { N\% }\end{array}$ & $\begin{array}{l}\text { Female } \\
\text { N\% }\end{array}$ & $p$-value* \\
\hline $\begin{array}{l}\text { Sleep Quality } \\
\text { Good } \\
\text { Poor }\end{array}$ & $\begin{array}{l}159(36.1) \\
281(63.9)\end{array}$ & $\begin{array}{l}79(36.7) \\
136(63.3)\end{array}$ & $\begin{array}{l}80(35.6) \\
145(64.4)\end{array}$ & 0.795 \\
\hline $\begin{array}{l}\text { Physical Activity Level } \\
\text { Physically Inactive } \\
\text { Moderate Active } \\
\text { High Active }\end{array}$ & $\begin{array}{l}276(62.7) \\
134(30.5) \\
30(6.8)\end{array}$ & $\begin{array}{l}113(52.6) \\
82(38.1) \\
20(9.3)\end{array}$ & $\begin{array}{l}163(72.4) \\
52(23.1) \\
10(4.4)\end{array}$ & $<0.001$ \\
\hline $\begin{array}{l}\text { Stress Level } \\
\text { Normal } \\
\text { Mild } \\
\text { Moderate } \\
\text { Severe } \\
\text { Extremely Severe }\end{array}$ & $\begin{array}{l}205(46.6) \\
57(13.0) \\
79(18.0) \\
72(16.4) \\
27(6.1)\end{array}$ & $\begin{array}{l}93(43.3) \\
29(13.5) \\
36(16.7) \\
44(20.5) \\
13(6.0)\end{array}$ & $\begin{array}{l}112(49.8) \\
28(12.4) \\
43(19.1) \\
28(12.4) \\
14(6.2)\end{array}$ & 0.217 \\
\hline $\begin{array}{l}\text { Numerical Measures Mean (SD) } \\
\text { Global PSQI } \\
\text { Days Physical } \\
\text { DASS Scores }\end{array}$ & $\begin{array}{l}6.7(2.9) \\
5.6(5.5) \\
16.1(10.8)\end{array}$ & $\begin{array}{l}6.6(2.9) \\
7.0(6.1) \\
17.0(10.7)\end{array}$ & $\begin{array}{l}6.9(2.9) \\
4.3(4.3) \\
15.2(10.8)\end{array}$ & $\begin{array}{l}0.242 \# \\
<0.001 \# \\
0.080 \#\end{array}$ \\
\hline
\end{tabular}

Notes: *Based on Chi-square test; ${ }^{\#}$ Based on independent $t$-test.

Abbreviation: PSQI, Pittsburgh Sleep Quality Index. 
Table 3 Factors Associated with Sleep Quality Among Study Participants

\begin{tabular}{|c|c|c|c|c|}
\hline \multicolumn{2}{|l|}{ Factors } & \multirow{2}{*}{$\begin{array}{l}\begin{array}{l}\text { Good } \\
\text { PSQI } \leqq 5\end{array} \\
72(43.9) \\
87(31.5)\end{array}$} & \multirow{2}{*}{$\begin{array}{l}\begin{array}{l}\text { Poor } \\
\text { PSQI > 5 }\end{array} \\
92(56.1) \\
189(68.5)\end{array}$} & \multirow{2}{*}{$\begin{array}{l}p \text {-value* } \\
0.009\end{array}$} \\
\hline $\begin{array}{l}\text { Physical } \\
\text { Activity }\end{array}$ & $\begin{array}{l}\text { Active } \\
\text { Inactive }\end{array}$ & & & \\
\hline $\begin{array}{l}\text { Physical } \\
\text { Activity Level }\end{array}$ & $\begin{array}{l}\text { High } \\
\text { Moderate } \\
\text { Inactive }\end{array}$ & $\begin{array}{l}17(56.7) \\
55(41.0) \\
87(31.5)\end{array}$ & $\begin{array}{l}13(43.3) \\
79(59.0) \\
189(68.5)\end{array}$ & 0.009 \\
\hline Stress & $\begin{array}{l}\text { Normal } \\
\text { Stressed }\end{array}$ & $\begin{array}{l}71(34.6) \\
159(37.4)\end{array}$ & $\begin{array}{l}134(65.4) \\
281(62.6)\end{array}$ & 0.540 \\
\hline Stress Level & $\begin{array}{l}\text { Normal } \\
\text { Mild } \\
\text { Moderate } \\
\text { Severe } \\
\text { Extremely Severe }\end{array}$ & $\begin{array}{l}71(34.6) \\
26(45.6) \\
26(32.9) \\
28(38.9) \\
8(29.6)\end{array}$ & $\begin{array}{l}134(65.4) \\
31(54.4) \\
53(67.1) \\
44(61.1) \\
19(70.4)\end{array}$ & 0.477 \\
\hline Caffeine Intake & $\begin{array}{l}\text { Yes } \\
\text { No }\end{array}$ & $\begin{array}{l}130(37.0) \\
29(32.6)\end{array}$ & $\begin{array}{l}221(63.0) \\
60(67.4)\end{array}$ & 0.435 \\
\hline How Often? & $\begin{array}{l}\text { Once a Week } \\
\text { More than once } \\
\text { a Week } \\
\text { Daily } \\
\text { Not at All }\end{array}$ & $\begin{array}{l}29(29.6) \\
51(38.3) \\
54(38.0) \\
23(38.3)\end{array}$ & $\begin{array}{l}69(70.4) \\
82(61.7) \\
88(62.0) \\
37(61.7)\end{array}$ & \\
\hline Smoking & $\begin{array}{l}\text { Yes } \\
\text { No }\end{array}$ & $\begin{array}{l}12(27.3) \\
147(37.1)\end{array}$ & $\begin{array}{l}32(72.7) \\
249(62.9)\end{array}$ & 0.197 \\
\hline
\end{tabular}

Note: *Based on Chi-square test.

Abbreviation: PSQI, Pittsburgh Sleep Quality Index.

\section{Discussion}

The present study aimed to evaluate the association between poor sleep quality and physical inactivity among Jazan University students. Previous studies conducted in Saudi Arabia investigated different aspects of sleep, mainly focusing on characterizing sleeping habits and disturbances, ${ }^{38}$ sleep patterns and predictors of poor sleep quality, ${ }^{11}$ sleep quality, $^{12}$ stress and sleep quality, ${ }^{14}$ and predictors of insomnia. ${ }^{39}$ Yet, we know very little about students' physical activity and sleep quality, especially in the Jazan region. Thus, the present study attempted to investigate the associations between exercise participation and sleep quality among students at a university in that area.

Our results revealed that more than half of the study participants $(62.7 \%)$ were physically inactive. These results are consistent with those reported by previous studies in Saudi Arabia. ${ }^{20-22,24}$ For example, a recent study reported a prevalence of physical inactivity ${ }^{24}$ of $58.0 \%$ and $42.0 \%$ among male and female King Khalid University students. In the present study, females were less likely to engage in vigorous physical activity than were males. The same pattern has been reported by many studies in the $\mathrm{KSA}^{24}$ and other countries ${ }^{40,41}$ among different cultures and different age groups. Gender differences between males and females in physical activity can be analysed in the context of Muslim countries' culture and the role of women in this culture. Social expectations require that women not exercise in mixedgender settings, and this reduces the opportunities available for women to be involved in any physical activity. $^{42-44}$ In many Middle Eastern Arab countries, athleticism is more linked to maleness, and vigorous activity and sports are inconsistent with femininity.

The major insight of the present study about sleep quality was that the majority of the study population had poor sleep quality (63.9\%), while only $36.6 \%$ had good sleep quality. This result is consistent with those of another study conducted at Jazan University (2013), which found that $64.4 \%$ of students had poor sleep quality and $35.6 \%$ had good sleep quality. ${ }^{12}$

The current study provides evidence of a high prevalence of psychological stress amongst students (53.4\%). The prevalence of stress in this study is comparable to that

Table 4 Sleep Quality According to Different Physical Activity Levels Among Study Participants

\begin{tabular}{|l|l|l|l|l|l|l|l|}
\hline \multirow{2}{*}{ PSQI Component } & \multicolumn{2}{l|}{ Physically Inactive } & \multicolumn{2}{l|}{ Moderately Active } & \multicolumn{2}{l|}{ Highly Active } & \multirow{2}{*}{$p$-value* } \\
\cline { 2 - 8 } & Mean & SD & Mean & SD & \multicolumn{2}{l|}{ Mean } & SD \\
\hline Sleep Efficiency & 1.2 & 0.9 & 1.0 & 0.9 & 1.1 & 0.8 & 0.552 \\
Sleep Onset & 1.8 & 0.9 & 1.6 & 0.9 & 1.6 & 0.8 & 0.064 \\
Sleep Duration & 1.6 & 1.2 & 1.5 & 1.1 & 1.1 & 1.0 & $0.040 \#$ \\
Sleep Disturbance & 1.2 & 0.6 & 1.1 & 0.6 & 1.1 & 0.7 & 0.160 \\
Sleep Assistance with Medication & 0.4 & 0.8 & 0.4 & 0.9 & 0.2 & 0.6 & 0.326 \\
Daytime Dysfunctions & 1.1 & 0.8 & 0.9 & 0.8 & 0.6 & 0.7 & 0.001 \\
Global PSQI & 7.1 & 2.8 & 6.4 & 2.9 & 5.1 & 2.6 & 0.011 \\
\hline
\end{tabular}

Notes: *Based on One-way ANOVA; "Based on Kruskal Wallis Test.

Abbreviation: PSQI, Pittsburgh Sleep Quality Index. 
Table 5 Regression Analysis of the Predictors of Good Sleep Quality

\begin{tabular}{|c|c|c|c|c|c|c|c|c|}
\hline \multirow[t]{4}{*}{ Factors } & \multicolumn{8}{|c|}{ Logistic Model* } \\
\hline & \multicolumn{4}{|c|}{ Univariate } & \multicolumn{4}{|c|}{ Multivariate } \\
\hline & \multirow[t]{2}{*}{$p$-value } & \multirow[t]{2}{*}{ OR } & \multicolumn{2}{|l|}{$95 \% \mathrm{Cl}$} & \multirow[t]{2}{*}{$p$-value } & \multirow[t]{2}{*}{ OR } & \multicolumn{2}{|l|}{$95 \% \mathrm{Cl}$} \\
\hline & & & Lower & Upper & & & Lower & Upper \\
\hline \multirow{5}{*}{$\begin{array}{l}\text { Physically Active } \\
\text { (Ref: Physically Inactive) } \\
\text { Stressed } \\
\text { (Ref: Not stressed) }\end{array}$} & 0.009 & 1.70 & 1.14 & 2.54 & 0.008 & 1.72 & 1.15 & 2.56 \\
\hline & 0.540 & 1.13 & 0.77 & 1.67 & 0.449 & 1.17 & 0.79 & 1.73 \\
\hline & \multicolumn{8}{|c|}{ Linear Regression Model\# } \\
\hline & \multicolumn{2}{|c|}{ Standardized Coefficients } & \multirow[t]{2}{*}{$\mathbf{t}$} & \multirow[t]{2}{*}{$p$-value } & \multicolumn{2}{|l|}{$95 \% \mathrm{Cl}$} & \multirow[t]{2}{*}{$\mathbf{F}$} & \multirow[t]{2}{*}{$p$-value } \\
\hline & $\beta$ & SE & & & Lower & Upper & & \\
\hline (Constant) & 7.04 & 0.285 & 24.70 & $<0.001$ & 6.48 & 7.60 & 6.92 & 0.001 \\
\hline Days Physical & -.167 & 0.025 & -3.53 & $<0.001$ & -.137 & -.039 & & \\
\hline DASS Scores & 0.049 & 0.013 & 1.03 & 0.304 & -.012 & 0.038 & & \\
\hline
\end{tabular}

Notes: *Outcome variable, (Poor/Good Sleep quality); ${ }^{\#}$ Outcome variable, Global Pittsburgh Sleep Quality Index (PSQI).

observed in other countries such as Pakistan ${ }^{45}(60 \%)$ and Thailand $^{46}(57 \%)$, but less than that in $\operatorname{Jordan}^{47}(70 \%)$ and higher than what was reported in Ethiopia ${ }^{48}(40 \%)$. In this study, the proportion of students with good sleep quality and adequate physical exercise was $43.9 \%$, which can be compared with those reporting a lack of participation in physical exercise (31.5\%). Few studies have been conducted to assess the association between sleep quality and exercise participation. Our results revealed that being physically active is significantly associated with good sleep quality, which is consistent with a study conducted in Taiwan. ${ }^{49}$

A meta-analysis of randomized trials assessing the change in sleep quality among middle-aged and older adults due to an exercise programme intervention suggested that physical activity could become an alternative non-pharmacological therapy for those who are complaining of sleep problems due to its moderately positive effect on total sleep duration, slow-wave sleep, and sleep onset latency. ${ }^{50}$ In addition, physical exercise, especially acute exercise, has been found to decrease the duration of rapid eye movement sleep; another study supported the positive effect exercise on the efficiency of sleep, wake time after the onset of sleep, and stage one sleep. ${ }^{51}$

Several limitations of the present study should be taken into consideration. First, the study is based on observational data derived from a sectional study design, which may not permit us to reach a conclusion on the direction of the association between physical activity and sleep quality, so the results should be interpreted carefully. Second, exercise participation assessments were gathered through a one-time, self-administered questionnaire. Third, since exercise behaviour might vary by time in the school year (eg, before or after examinations or at the beginning or end of the semester), there may have been measurement error in exercise assessment. Further, we conducted our research based on student reporting rather than other more objective methods like clinical examinations. Finally, we investigated the relationship between physical activity and sleep quality at only one Saudi university due to the difficulty in securing permission from other universities. We recommend that this relationship be further examined among different Saudi universities.

\section{Conclusions}

This study highlighted that the majority of Jazan University students had poor sleep quality and were physically inactive. University students who exercised regularly reported having better sleep quality than those who exercised less. The results of this study could be useful to health planners and policymakers interested in developing evidence-based prevention and therapeutic strategies for students who are physically inactive and have poor sleep quality. Controlled experimental studies are needed to verify the causal relationships among these factors. 


\section{Acknowledgments}

The authors would like to thank the students of Jazan University who sacrificed their valuable time by taking part in the survey. The authors also acknowledge, with much appreciation, the input and participation of Yousef Ali Abdali, Abdullah Ahmed Al Faqih, and Abdullaziz Khalid Almalki, who contributed greatly to our data collection.

\section{Author Contributions}

The authors contributed equally to the work.

\section{Disclosure}

The authors declare that they have no competing interests.

\section{References}

1. AlDabal L. Metabolic, endocrine, and immune consequences of sleep deprivation. Open Respir Med J. 2011;5(1):31-43. doi:10.2174/ 1874306401105010031

2. Disorders S. Sleep disorders and sleep deprivation. 2015. doi: $10.17226 / 11617$

3. Ramar K, Olson EJ. Management of common sleep disorders. $A m$ Fam Physician. 2013;88(4):231-238.

4. Wallander MA, Johansson S, Ruigómez A, Rodríguez LA, Jones R. Morbidity associated with sleep disorders in primary care: a longitudinal cohort study. Prim Care Companion $J$ Clin Psychiatry. 2007;9(5):338. doi:10.4088/PCC.v09n0502

5. Lim J, Dinges DF. A meta-analysis of the impact of short-term sleep deprivation on cognitive variables. Psychol Bull. 2010;136 (3):375-389. doi:10.1037/a0018883.A

6. Mirghani HO, Mohammed OS, Almurtadha YM, Ahmed MS. Good sleep quality is associated with better academic performance among Sudanese medical students Medical Education. BMC Res Notes. 2015;8(1):4-8. doi:10.1186/s13104-015-1712-9

7. Taylor DJ, Bramoweth AD, Grieser EA, Tatum JI, Roane BM. Epidemiology of insomnia in college students: relationship with mental health, quality of life, and substance use difficulties. Behav Ther. 2013;44(3):339-348. doi:10.1016/j.beth.2012.12.001

8. Schlarb AA, Friedrich A, Claßen M. Sleep problems in university students-an intervention. Neuropsychiatr Dis Treat. 2017;13:1989. doi:10.2147/NDT.S142067

9. Alsanosy RM, Mahfouz MS. Khat chewing among students of higher education in Jazan Region, Saudi Arabia: prevalence, pattern, and related factors. Biomed Res Int. 2013;2013:1-7. doi:10.1155/2013/ 487232

10. Mohamed BA, Mahfouz MS, Badr MF. Food selection under stress among undergraduate students in Riyadh, Saudi Arabia. Psychol Res Behav Manag. 2020;13:211. doi:10.2147/PRBM.S236953

11. Al-Qahtani M, Siddiqui AF, Al-Qahtani A, Al-Amri H, Al-Musa H, Al-Shahrani M. Sleep patterns and predictors of poor sleep quality among medical students in King Khalid University, Saudi Arabia. Malaysian $J$ Med Sci. 2016;23(6):94-102. doi:10.21315/ mjms2016.23.6.10

12. Mahfouz MS, Ageely H, Al-Saruri SM, et al. Sleep quality among students of the faculty of medicine in Jazan University, Saudi Arabia. Middle East J Sci Res. 2013;16(4):508-513. doi:10.5829/idosi. mejsr.2013.16.04.75151

13. Alsaggaf MA, Wali SO, Merdad RA, Merdad LA. Sleep quantity, quality, and insomnia symptoms of medical students during clinical years: relationship with stress and academic performance. Saudi Med J. 2016;37(2):173-182. doi:10.15537/smj.2016.2.14288
14. Almojali AI, Almalki SA, Alothman AS, Masuadi EM, Alaqeel MK. The prevalence and association of stress with sleep quality among medical students. J Epidemiol Glob Health. 2017;7(3):169-174. doi:10.1016/j.jegh.2017.04.005

15. Al-Khani AM, Sarhandi MI, Zaghloul MS, Ewid M, Saquib N. A cross-sectional survey on sleep quality, mental health, and academic performance among medical students in Saudi Arabia. BMC Res Notes. 2019;12(1):1-5. doi:10.1186/s13104-019-4713-2

16. Ahmed AE, Al-Jahdali F, AlALwan A, et al. Prevalence of sleep duration among Saudi adults. Saudi Med J. 2017;38(3):276-283. doi:10.15537/smj.2017.3.17101

17. Al-Hazzaa HM, Musaiger A, Abahussain N, Al-Sobayel H, Qahwaji D. Prevalence of short sleep duration and its association with obesity among adolescents 15 - to 19 -year olds: a cross-sectional study from three major cities in Saudi Arabia. Ann Thorac Med. 2012;7(3):133-139. doi:10.4103/1817-1737.98845

18. Caspersen CJ, Powell KE, Christenson GM, Christenson G. Physical activity, exercise, and physical fitness: definitions and distinctions for health-related research. Public Health Rep. 1985;100(2):126-131. doi: $10.2307 / 20056429$

19. Warburton DE, Nicol CW, Bredin SS. Health benefits of physical activity: the evidence. Cmaj. 2006;174(6):801-809. doi:10.1503/ cmaj.051351

20. Al-Hazzaa HM. Physical inactivity in Saudi Arabia revisited: a systematic review of inactivity prevalence and perceived barriers to active living. Int J Health Sci (Qassim). 2018;12(6):50-64.

21. Al-Hazzaa HM. The public health burden of physical inactivity in Saudi Arabia. J Family Community Med. 2004;11(2):45-51.

22. Alsadhan N, Aboshaiqah AE, Tumala RB, et al. Health promoting lifestyle of university students in Saudi Arabia: a cross-sectional assessment. BMC Public Health. 2018;18(1):1-10. doi:10.1186/ s12889-018-5999-z

23. Alshammari SA, Al-Drees A, Al-Zhrani AA, et al. Physical activity and academic achievement among the medical students: a cross-sectional study. Med Teach. 2016;38(sup1):S66-S72. doi:10.3109/0142159x.2016. 1142516

24. Awadalla NJ, Aboelyazed AE, Hassanein MA, et al. Assessment of physical inactivity and perceived barriers to physical activity among health college students, south-western Saudi Arabia. East Mediterr Health J. 2014;20(10):596-604. doi:10.26719/2014. 20.10.596

25. Hurdiel R, Watier T, Honn K, Pezé T, Zunquin G, Theunynck D. Effects of a 12-week physical activities programme on sleep in female university students. Res Sport Med. 2017;25(2):191-196. doi:10.1080/15438627.2017.1282354

26. de Vries JD, van Hooff MLM, Geurts SAE, Kompier MAJ. Exercise as an Intervention to reduce study-related fatigue among university students: a two-arm parallel randomized controlled trial. PLoS One. 2016;11(3):e0152137. doi:10.1371/journal.pone.0152137

27. Shih K-S, Chen Y-H, Hwang K-L, Chang C-M, Chang S-P, Chi C-P. Association between exercise participation and quality of sleep and life among university students in Taiwan. Asia Pacific J Public Heal. 2016;28(4):356-367. doi:10.1177/1010539516645160

28. Ghrouz AK, Pandi-Perumal SR, BaHammam AS, Noohu MM, Warren Spence D, Dilshad Manzar M. Physical activity and sleep quality in relation to mental health among college students. Sleep Breath. 2019;23(2):627-634. doi:10.1007/s11325-01901780-z

29. Wu X, Tao S, Zhang Y, Zhang S, Tao F. Low physical activity and high screen time can increase the risks of mental health problems and poor sleep quality among Chinese college students. PLoS One. 2015;10(3):1-11. doi:10.1371/journal.pone.0119607

30. Lang C, Brand S, Feldmeth AK, Holsboer-Trachsler E, Pühse U, Gerber M. Increased self-reported and objectively assessed physical activity predict sleep quality among adolescents. Physiol Behav. 2013;120:46-53. doi:10.1016/j.physbeh.2013.07.001 
31. Feng Q, Le ZQ, Du Y, Ye YL, He QQ. Associations of physical activity, screen time with depression, anxiety and sleep quality among Chinese college freshmen. PLoS One. 2014. doi:10.1371/ journal.pone.0100914

32. Vargas PA, Flores M, Robles E. Sleep quality and body mass index in college students: the role of sleep disturbances. $\mathrm{J} \mathrm{Am} \mathrm{Coll} \mathrm{Heal.}$ 2014;62(8):534-541. doi:10.1080/07448481.2014.933344

33. Booth M. Assessment of physical activity: an international perspective. Res $Q$ Exerc Sport. 2000;71(sup2):114-120. doi:10.1080/02701367.2000.11082794

34. Smyth C. The Pittsburgh Sleep Quality Index (PSQI). Director. 2000;8(1):28-29. doi:10.3928/0098-9134-19991201-10

35. Lovibond PF, Lovibond $\mathrm{SH}$. The structure of negative emotional states: comparison of the depression anxiety stress scales (DASS) with the Beck Depression and Anxiety Inventories. Behav Res Ther. 1995;33(3):335-343. doi:10.1016/0005-7967(94)00075-U

36. Forde C. Scoring the international physical activity questionnaire (IPAQ) exercise prescription for the prevention and treatment of disease. 2005.

37. Lovibond SH, Lovibond PF Overview of the DASS and its uses. Available from: www2. psy. unsw. edu. au/Groups/Dass/over. htm. Accessed February 15, 2009.

38. Al-Tannir MA, Kobrosly SY, Al-Badr AH, Salloum NA, Altannir YM, Sakkijha HM. Characterizing sleeping habits and disturbances among Saudi adults. Saudi Med J. 2016;37(12):1363-1371. doi:10.15537/smj.2016.12.17373

39. Albasheer OB, Al Bahhawi T, Ryani MA, et al. Prevalence of insomnia and relationship with depression, anxiety and stress among Jazan University students: a cross-sectional study. Cogent Psychol. 2020;7(1):1789424. doi:10.1080/23311908.2020.1789424

40. Wei CN, Harada K, Ueda K, Fukumoto K, Minamoto K, Ueda A. Assessment of health-promoting lifestyle in Japanese university students. Environ Health Prev Med. 2012;17:222-227. doi:10.1007/ s12199-011-0244-8

41. Sousa P, Gaspar P, Fonseca H, Hendricks C, Murdaugh C. Health promoting behaviors in adolescence: validation of the Portuguese version of the adolescent lifestyle profile. Journal de Peditria. 2015;91(4):358-365. doi:10.1016/j.jped.2014.09.005
42. Mabry RM, Reeves MM, Eakin EG, Owen N. Evidence of physical activity participation among men and women in the countries of the Gulf cooperation council: a review. Obes Rev. 2010;11(6):457-464. doi:10.1111/j.1467-789X.2009.00655.x

43. Oyewole OO, Odusan O, Kolawole S. O, Idowu AO. Physical activity among type-2 diabetic adult Nigerians. Ann Afr Med. 2014;13 (4):189-194. doi:10.4103/1596-3519.142290

44. Ogu OC. Social situations affecting the sporting experiences of working-class women in Nigeria: a challenge to sport for all. Int Sports Stud. 1999;21(2):55-64.

45. Waqas A, Khan S, Sharif W, Khalid U, Ali A. Association of academic stress with sleeping difficulties in medical students of a Pakistani medical school: a cross sectional survey. PeerJ. 2015;12 (3):e840. doi:10.7717/peerj.840

46. Saipanish R. Stress among medical students in a Thai medical school. Med Teach. 2003;25(5):502-506. doi:10.1080/014215903100013 6716

47. Abu-Ghazaleh SB, Rajab LD, Sonbol HN. Psychological stress among dental students at the University of Jordan. J Dent Educ. 2011;75(8):1107-1114. doi:10.1002/j.0022-0337.2011.75.8.tb05156. $\mathrm{X}$

48. Dachew BA, Bisetegn TA, Gebremariam RB. Prevalence of mental distress and associated factors among undergraduate students of the University of Gondar, Northwest Ethiopia: a cross-sectional institutional based study. PLoS One. 2015;10(3):e0119464. doi:10.1371/ journal.pone.0119464

49. Chang SP, Huang SC, Chen YH, Wright R, Liao LC. The relationship between sleep quality and the exercise participation behavior of college students in the Central Taiwan Region. Int J Sport Exerc Psychol. 2013;5(2):13-18.

50. Yang PY, Ho KH, Chen HC, Chien MY. Exercise training improves sleep quality in middle-aged and older adults with sleep problems: a systematic review. J Physiother. 2012;58(3):157-163. doi:10.1016/ S1836-9553(12)70106-6

51. Kredlow MA, Capozzoli MC, Hearon BA, Calkins AW, Otto MW. The effects of physical activity on sleep: a meta-analytic review. J Behav Med. 2015;38(3):427-449. doi:10.1007/s10865-015-9617-6
Nature and Science of Sleep

\section{Publish your work in this journal}

Nature and Science of Sleep is an international, peer-reviewed, open access journal covering all aspects of sleep science and sleep medicine, including the neurophysiology and functions of sleep, the genetics of sleep, sleep and society, biological rhythms, dreaming, sleep disorders and therapy, and strategies to optimize healthy sleep.
The manuscript management system is completely online and includes a very quick and fair peer-review system, which is all easy to use. Visit http://www.dovepress.com/testimonials.php to read real quotes from published authors. 